\title{
Phenoxyimine Ligand Molecular Structure Influence on Reversible Magnesium Electrode Reaction in a Magnesium Chloride Complex
}

\author{
Minato EGASHIRA ${ }^{\mathrm{a}, *, \S}$ (]) and Kouki MATSUBARA ${ }^{\mathrm{b}}$ \\ a College of Bioresource Sciences, Nihon University, 1866 Kameino, Fujisawa, Kanagawa 252-0880, Japan \\ b Faculty of Science, Fukuoka University, 8-19-1 Nanakuma, Jonan-ku, Fukuoka 814-0180, Japan
}

*Corresponding author: egashira.minato@nihon-u.ac.jp

\begin{abstract}
Non-aqueous electrolytes containing magnesium chloride complex in which magnesium is coordinated by synthesized phenoxyimine ligand have unique properties for magnesium deposition and dissolution. Those properties have been compared using ligands with different terminal groups. For electrochemical and Raman spectroscopic studies, mixed electrolytes were prepared by dissolving a phenoxyiminemagnesium-chloride complex and magnesium [bis(trifluoromethane sulfonyl)imide] in triglyme solvent. An electrolyte containing phenoxyimine with an $n$-butyl terminal group shows higher Coulombic efficiency of magnesium deposition than the electrolyte prepared with dimethylamine-terminated phenoxyimine, probably because of preferred formation of active triglyme-magnesium-chloride coordinated cations. By contrast, adding aluminum chloride to the electrolyte with n-butyl-terminated phenoxyimine adversely affected reversible magnesium deposition, probably because trapping of chloride occurred preferentially.
\end{abstract}

(C) The Author(s) 2021. Published by ECSJ. This is an open access article distributed under the terms of the Creative Commons Attribution 4.0 License (CC BY, http://creativecommons.org/licenses/by/4.0/), which permits unrestricted reuse of the work in any medium provided the original work is properly cited. [DOI: 10.5796/electrochemistry.21-00041].

Keywords : Magnesium Batteries, Magnesium Chloride Electrolyte, Phenoxyimine Ligand

\section{Introduction}

To meet increasing demands for alternative secondary batteries with safety, low cost, and high energy density, magnesium batteries have been investigated intensively during the past decade. ${ }^{1,2}$ High barriers against realization of commercially available magnesium batteries lie in the reversibility of magnesium negative electrodes. ${ }^{2-5}$ Apart from lithium, the magnesium electrode reaction and magnesium deposition and dissolution occur in only a few nonaqueous electrolyte systems. An ethereal solution of alkylmagnesium chloride complex, Grignard reagent, has received attention from the earliest stages of magnesium battery research ${ }^{6,7}$ because it promotes reversible magnesium deposition-dissolution with small overpotential. In the first presented magnesium battery prototype, a stoichiometric mixture of alkylmagnesium chloride and a Lewis acid, $\mathrm{Mg}\left[\mathrm{AlCl}_{4-n} \mathrm{R}_{n}\right]_{2}$ (R: alkyl) was used. ${ }^{8}$ In such an electrolyte, multi-nuclear magnesium-chloride clusters such as $\mu-\mathrm{Mg}_{2} \mathrm{Cl}_{3}{ }^{+}$with coordinating solvent molecules are formed under some dissociation equilibrium including Schlenk equilibrium: they are assumed as active species to promote reversible magnesium deposition. ${ }^{9-11}$ According to assumptions about the active species, some probability exists of promoting reversible magnesium deposition also in solutions containing high concentrations of $\mathrm{MgCl}_{2}$. Indeed, reversible magnesium deposition has been reported in ethereal solutions of magnesium[bis(trifluoromethane sulfonyl)amide]$\left[\mathrm{Mg}(\mathrm{TFSA})_{2}\right]$ and $\mathrm{MgCl}_{2},{ }^{12-14}$ and ethereal solutions of $\mathrm{MgCl}_{2}$ with $\mathrm{AlCl}_{3}$ or other Lewis acids. ${ }^{15-17}$ The chloride-containing species is expected to dissolve the passivation layer on the magnesium surface and to support smooth conversion from metallic magnesium to divalent ion. ${ }^{16-19}$ Such chloride-containing electrolytes are adversely affected by the possibility of corroding metallic components and by the low anodic limit. ${ }^{3,20}$ Recent progress on

${ }^{\S}$ ECSJ Active Member

M. Egashira (D) orcid.org/0000-0003-1405-6075 magnesium batteries has yielded several attractive magnesium salts based on boron-based weakly coordinated anions, ${ }^{21,22}$ which also promote reversible magnesium deposition with moderate overpotential and which have higher anodic stability than chloride-based systems. However, the chloride-containing electrolytes are still beneficial in terms of low preparation cost and low overpotential of magnesium deposition. Moreover, some reports have suggested that the existence of chloride ion in electrolyte is favorable for reactions on a positive electrode. ${ }^{23,24}$ Therefore, the authors believe that chloride-containing electrolytes are still powerful candidates for $2 \mathrm{~V}$ class practical magnesium battery electrolytes with such positive electrodes as Chevrel phase or sulfur.

For these magnesium chloride-based electrolytes, the coordination state of magnesium influences the stability, Schlenk equilibrium, and solubility in various solvents. Some coordinator materials having an electron-withdrawing site, as do alkoxyde and hexamethyl disilazide (HMDS), can improve the stability while retaining the reversibility of magnesium deposition via the formation of a complex cation with magnesium. ${ }^{25-28}$ The authors have proposed a phenoxyimine ligand having bi-dentate sites. The ligand is easily substituted to alkyl in alkylmagnesium halide, to which it provides a magnesium halide complex that is stable, even under ambient moisture. The mixed electrolyte in which the resulted magnesium chloride complex is dissolved in $\operatorname{Mg}(\mathrm{TFSA})_{2} /$ triglyme improves the magnesium deposition-dissolution reversibility and overpotential. ${ }^{29,30}$ The phenoxyimine ligand delivers an ionic complex in which the ligand forms a complex anion against a multi-nuclear magnesium-chloride-solvent complex cation. Indeed, one benefit of such a ligand is the possibility of designing the molecular structure for tuning the properties of magnesium chloride complex and also the resultant electrolyte. Apart from practical battery usage, the present study is aimed to display two synthesized phenoxyimine ligands having different terminal groups, with intensive assessment of how the phenoxyimine molecular structure affects the magnesium electrode reaction. 




Figure 1. Molecular structure and abbreviations of the phenoxyimine ligands used in this study.

\section{Experimental}

Phenoxyimine molecules for ligands have been synthesized as described earlier in the literature, ${ }^{29}$ with addition of the corresponding imine to salicyl aldehyde. The structures of phenoxyimine ligands prepared for this study are presented in Fig. 1. Notations of these ligands are, as the figure shows, a $\mathrm{L}_{x}$ with terminating moiety $x$, dimethylamine DMA, or n-butyl BU. The authors expected that the DMA terminating moiety also participates in the coordination to magnesium and somewhat stabilizes the coordination. The purity and the correspondence of the molecular structure of the product were assure by ${ }^{1} \mathrm{H}-\mathrm{NMR}$. The phenoxyimine was then dissolved in THF (organic synthesis grade, stabilizer non-inclusive; Kanto Chemical Co. Ltd., Japan) as the concentration of the phenoxyimine was $1.0 \mathrm{~mol} \mathrm{dm}^{-3}$. The water content of solvent was confirmed as lower than $30 \mathrm{ppm}$ using a Karl-Fisher titrator (MKC-710; Kyoto Electronics Mfg. Co., Ltd., Japan). The magnesium halide complex was obtained by mixing the phenoxyimine/THF solution and an excess amount of methylmagnesium chloride/THF solution (ca. $1.8-2.2 \mathrm{~mol} \mathrm{dm}^{-3}$, Kanto Chemical Co. Ltd., Japan) during 4 days. The reaction is expected to occur between the phenol moiety (Ph-OH) in a $\mathrm{L}_{x}$ molecule and $\mathrm{CH}_{3} \mathrm{MgCl}$ as shown in following equation:

$$
\mathrm{Ph}-\mathrm{OH}\left(\text { in } \mathrm{L}_{x}\right)+\mathrm{CH}_{3} \mathrm{MgCl} \rightarrow \mathrm{Ph}-\mathrm{OMgCl}+\mathrm{CH}_{4} \uparrow
$$

The reaction product has been checked to contain no residual methylmagnesium halide by ${ }^{1} \mathrm{H}-\mathrm{NMR}$, of which spectra are shown in Fig. 2. The disappearance of phenolic hydrogen clearly indicates the relevance of the above reaction scheme. It is observed that the peak at $-0.67 \mathrm{ppm}$ in the spectrum for the methyl in $\mathrm{CH}_{3} \mathrm{MgCl}$ completely disappears in the spectra for each reaction product. Also, the spectra region between 1.0 and $3.0 \mathrm{ppm}$ indicates that the residual methylmagnesium halide reacts with the alpha-carbon of the imine to provide amino moiety. The magnesium halide complex was collected by evaporation of the THF solvent. The prescribed amount of the complex was dissolved in the corresponding solution of $\operatorname{Mg}(\mathrm{TFSA})_{2}$ (battery grade; Kishida Pure Chemical Co. Ltd., Japan) in triglyme (battery grade; Kanto Chemical Co. Ltd., Japan). The water content of the $\operatorname{Mg}(\mathrm{TFSA})_{2} /$ triglyme solution was also checked as lower than $30 \mathrm{ppm}$. In some cases, aluminum chloride ( $\mathrm{AlCl}_{3}$; Kanto Chemical Co. Ltd., Japan) was added to the $\mathrm{L}_{x} \mathrm{MgCl} /$ $\mathrm{Mg}(\mathrm{TFSA})_{2}$ /triglyme solution so that the content of $\mathrm{AlCl}_{3}$ was $0.1 \mathrm{~mol} \mathrm{dm}^{-3}$. The solution structures were assessed using a laser Raman spectrometer (Agility; BeySpec Inc., Japan). The laser wavelength was $1064 \mathrm{~nm}$, with lower energy than conventional green laser of $532 \mathrm{~nm}$ wavelength, thereby preventing decomposition of the complex by laser irradiation. Peak separation based on the Lorenzian-Gaussian model for the collected spectra was then conducted using Rapswin software.

Computational estimation of the structure of ligand coordination to magnesium chloride was conducted using Gaussian09 software. The method and basis function were, respectively, RB3LYP and $6-$ $31+\mathrm{G}$.
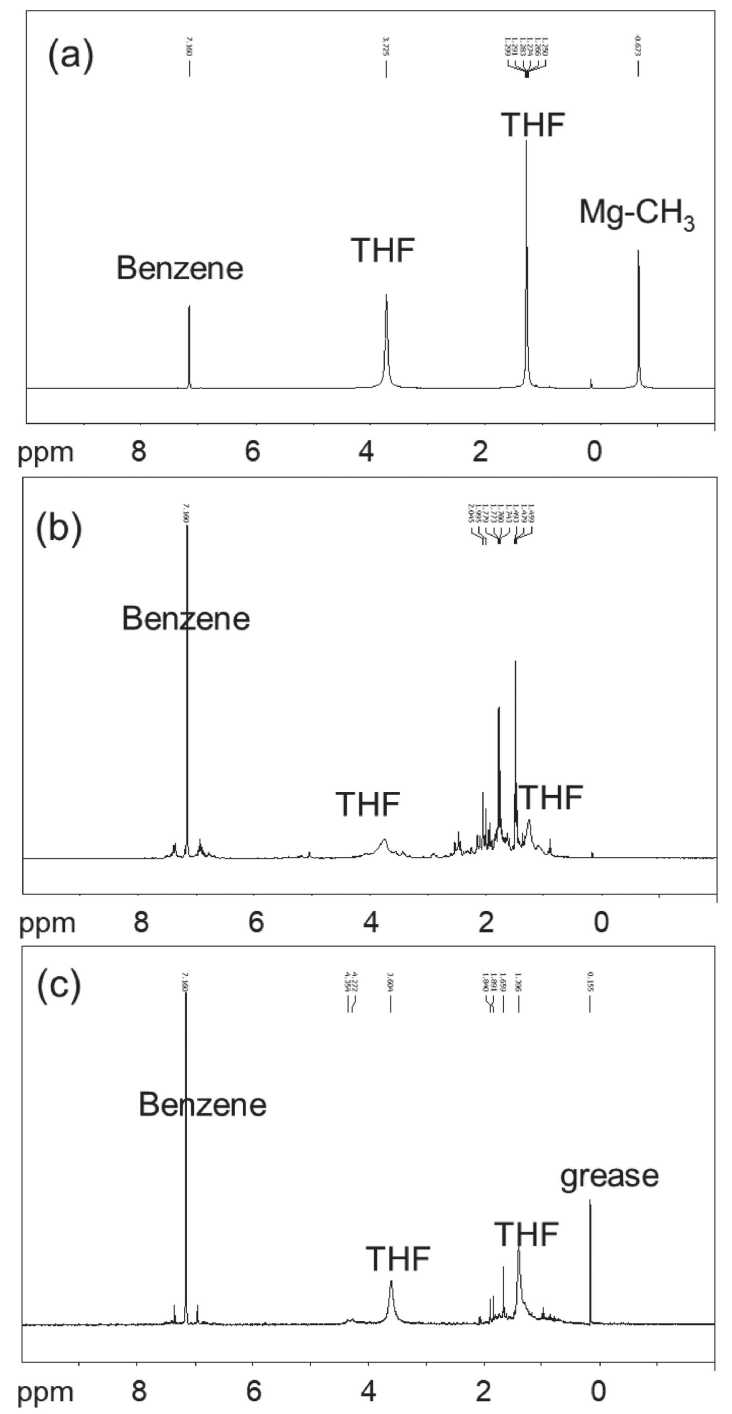

Figure 2. ${ }^{1} \mathrm{H}-\mathrm{NMR}$ spectra of the reaction products between $\mathrm{CH}_{3} \mathrm{MgCl} / \mathrm{THF}$ and phenoxyimine $\mathrm{L}_{x}$ molecules. Solvent: $\mathrm{d}^{6}-$ benzene. (a) $\mathrm{CH}_{3} \mathrm{MgCl} / \mathrm{THF}$ (as comparison). (b) Product from $\mathrm{L}_{\mathrm{DMA}}$. (c) Product from $\mathrm{L}_{\mathrm{BU}}$.

The electrochemical magnesium deposition was performed in a prepared electrolyte solution using commercial three-electrode cell (BAS Inc., Japan) with a gold plate (the Nilaco Corp., Japan) as a working electrode, a magnesium plate (The Nilaco Corp., Japan) attached with a platinum wire as a counter electrode, and a silver wire in $\mathrm{AgNO}_{3}$ /acetonitrile solution filled in a glass tube with a Vicor $^{\circledR}$ glass as a reference electrode. After the cell was assembled in a glove box filled with argon gas, it was placed in a sealed container. The magnesium deposition-dissolution test was conducted by cyclic voltammetry using a potentiostat (Solartron 1286) under $5.0 \mathrm{mV} \mathrm{s}^{-1}$ of scan rate, at potentials of $-3.5 \mathrm{~V}$ and $1.0 \mathrm{~V}$ versus the reference electrode. The cell container was placed in a temperature chamber to be three cycles at $298 \mathrm{~K}$.

\section{Results and Discussion}

Cyclic voltammograms are shown in Figs. 3(a-c) for magnesium deposition-dissolution in (a) $1.5 \mathrm{~mol} \mathrm{dm}^{-3} \mathrm{Mg}(\mathrm{TFSA})_{2} /$ triglyme, the mixed electrolytes of (b) $0.5 \mathrm{~mol} \mathrm{dm}^{-3}$ of $\mathrm{L}_{\mathrm{DMA}} \mathrm{MgCl}$ and $1.0 \mathrm{~mol} \mathrm{dm}^{-3} \mathrm{Mg}(\mathrm{TFSA})_{2}$, and (c) the substituted electrolyte of $\mathrm{L}_{\mathrm{BU}} \mathrm{MgCl}$ to $\mathrm{L}_{\mathrm{DMA}} \mathrm{MgCl}$. The $\mathrm{Mg}(\mathrm{TFSA})_{2} /$ triglyme electrolyte provides ca. $1.3 \mathrm{~V}$ of overpotential between the onset potential 

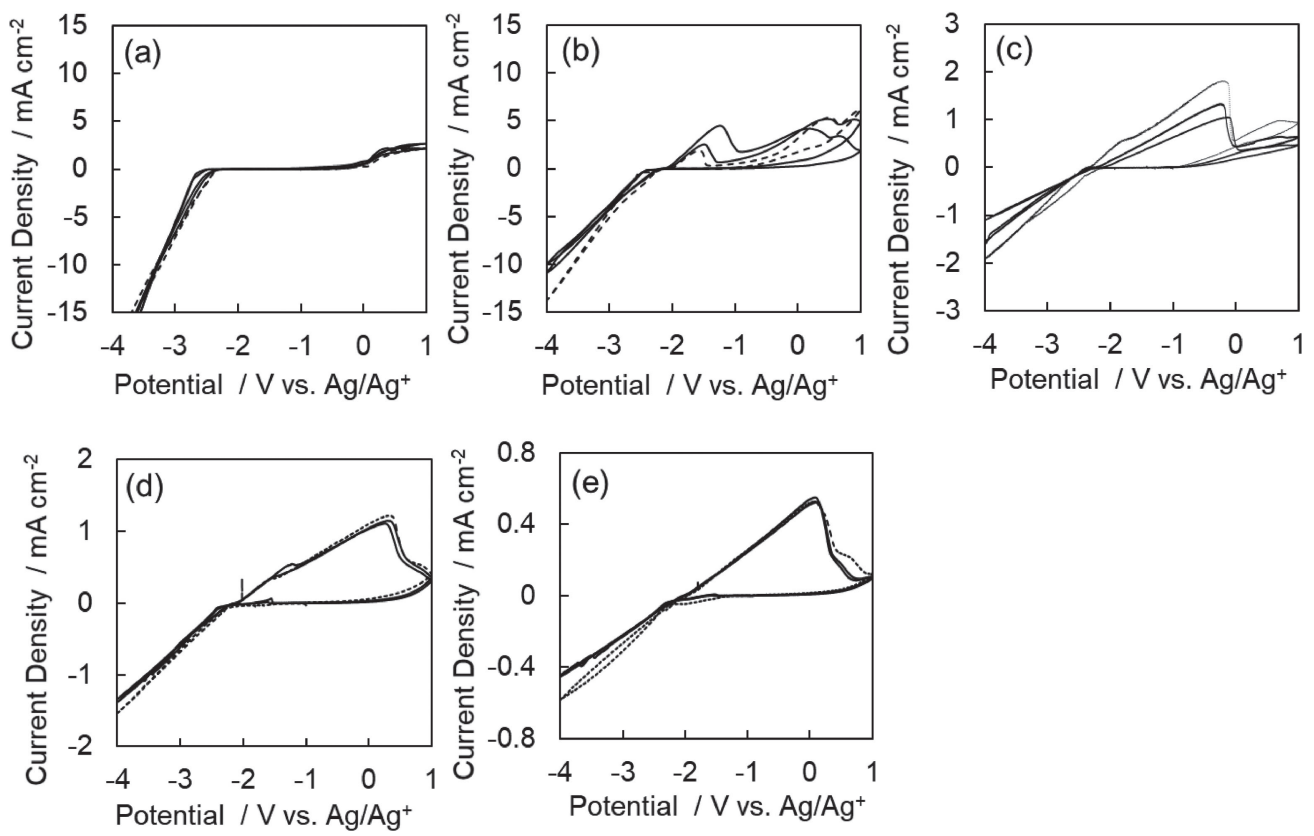

Figure 3. Cyclic voltammograms of magnesium deposition-dissolution in $\mathrm{Mg}(\mathrm{TFSA})_{2} / \mathrm{L}_{x} \mathrm{MgCl} /$ triglyme electrolytes. Electrolyte:

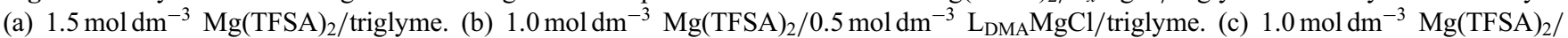
$0.5 \mathrm{~mol} \mathrm{dm}^{-3} \quad \mathrm{~L}_{\mathrm{BU}} \mathrm{MgCl} /$ triglyme. (d) $1.0 \mathrm{~mol} \mathrm{dm}^{-3} \quad \mathrm{Mg}(\mathrm{TFSA})_{2} / 0.5 \mathrm{~mol} \mathrm{dm}^{-3} \quad \mathrm{~L}_{\mathrm{DMA} \mathrm{MgCl} / \text { triglyme with }} 0.1 \mathrm{~mol} \mathrm{dm}^{-3} \quad \mathrm{AlCl}_{3}$. (e) $1.0 \mathrm{~mol} \mathrm{dm}^{-3} \mathrm{Mg}$ (TFSA $)_{2} / 0.5 \mathrm{~mol} \mathrm{dm}^{-3} \mathrm{~L}_{\mathrm{BU}} \mathrm{MgCl} /$ triglyme with $0.1 \mathrm{~mol} \mathrm{dm}^{-3} \mathrm{AlCl}_{3}$. 1-3 cycles, first cycle is shown by dotted lines. Scan rate, $5 \mathrm{mV} \mathrm{s}^{-1}$; potential range, -4.0 to $1.0 \mathrm{~V}$ vs. $\mathrm{Ag} / \mathrm{Ag}^{+}$; Temp., $298 \mathrm{~K}$.

(where the absolute value for the current density becomes below $0.1 \mathrm{~mA} \mathrm{~cm}^{-2}$, at the reverse direction on reduction) of magnesium deposition $\left(-2.3 \mathrm{~V}\right.$ vs. $\left.\mathrm{Ag} / \mathrm{Ag}^{+}\right)$and dissolution $(-1.0 \mathrm{~V})$ potentials. By contrast, the coexistence of a $\mathrm{L}_{x} \mathrm{MgCl}$ complex salt reduces the overpotential to $0.4 \mathrm{~V}$. The deposition of magnesium in the potential region below $-2.2 \mathrm{~V}$ in the $\mathrm{L}_{\mathrm{DMA}} \mathrm{MgCl}$-containing electrolyte was observed and reported previously together with the similar voltammogram data. ${ }^{29}$ Therefore, the reduction current below $-2.2 \mathrm{~V}$ and the oxidation one above $-2.2 \mathrm{~V}$ can be assumed as reversible magnesium deposition and dissolution, respectively. The appearance of magnesium dissolution current of magnesium deposition is developed by the coexistence of $\mathrm{L}_{x} \mathrm{MgCl}$. The voltammogram in the ternary electrolyte containing $\mathrm{L}_{\mathrm{DMA}} \mathrm{MgCl}$ shows two peaks of the oxidation current at $-1.3 \mathrm{~V}$ and $0.5 \mathrm{~V}$. Similar feature has been reported previously for the mixed salt electrolyte of $\mathrm{Mg}(\mathrm{TFSA})_{2}$ with $\mathrm{MgCl}_{2}$ in $\mathrm{THF},{ }^{13}$ and thus may be explained by the inhomogeneity of magnesium deposition likely because of the insufficient amount of $\mathrm{Cl}$-containing active species.

The coexistence of $\mathrm{L}_{x} \mathrm{MgCl}$ in $\mathrm{Mg}(\mathrm{TFSA})_{2}$ /triglyme electrolyte improved the Coulombic efficiency of magnesium deposition and dissolution. The extent of the positive effect depends on the ligand structure. Although the Coulombic efficiency of magnesium deposition-dissolution in $\operatorname{Mg}(\mathrm{TFSA})_{2}$ /triglyme is as low as $10 \%$, the Coulombic efficiency values of magnesium deposition-dissolution in the electrolytes containing $\mathrm{L}_{\mathrm{DMA}} \mathrm{MgCl}$ and $\mathrm{L}_{\mathrm{BU}} \mathrm{MgCl}$ calculated respectively from these voltammograms are $43 \%$ and $88 \%$. It is noteworthy that these values are apparent ones because the oxidation current includes the contribution of anodic decomposition of the electrolyte, which would not isolate from the dissolution current of magnesium.

The reduction current at $-2.2 \mathrm{~V}$ in the $\mathrm{L}_{\mathrm{BU}} \mathrm{MgCl} / \mathrm{Mg}(\mathrm{TFSA})_{2} /$ triglyme is markedly lower than those in $\mathrm{Mg}(\mathrm{TFSA})_{2} /$ triglyme and $\mathrm{L}_{\mathrm{DMA}} \mathrm{MgCl} / \mathrm{Mg}(\mathrm{TFSA})_{2}$ /triglyme. Such low current suggests that the mobility of magnesium species is low in the $\mathrm{L}_{\mathrm{BU}} \mathrm{MgCl}-$ containing electrolyte. The Arrhenius-manner temperature dependences of the conductivities of the $\mathrm{L}_{x} \mathrm{MgCl} / \mathrm{Mg}(\mathrm{TFSA})_{2} /$ triglyme
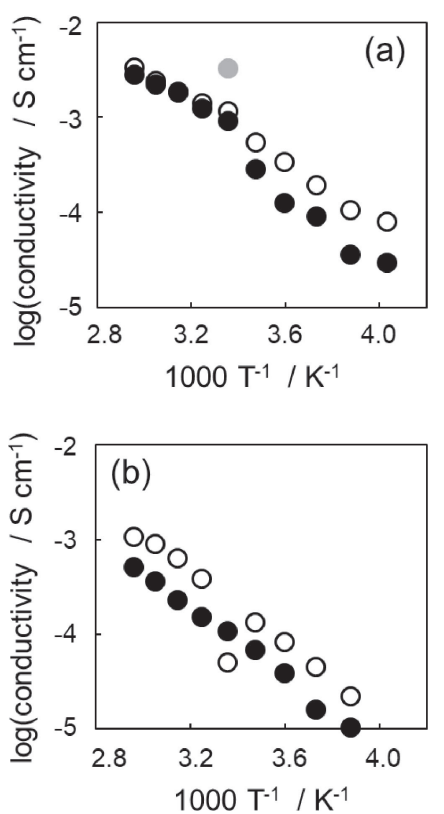

Figure 4. Arrhenius plots of the conductivity of the $\mathrm{L}_{x} \mathrm{MgCl} /$ $\mathrm{Mg}(\mathrm{TFSA})_{2} /$ triglyme. Symbols. Open circle: $\mathrm{L}_{\mathrm{DMA}} \mathrm{MgCl}$. Filled circle: $\mathrm{L}_{\mathrm{BU}} \mathrm{MgCl}$. Grey circle: $1.5 \mathrm{~mol} \mathrm{dm}^{-3} \mathrm{Mg}(\mathrm{TFSA})_{2} /$ triglyme. Concentration of $\mathrm{L}_{x} \mathrm{MgCl}-\mathrm{Mg}(\mathrm{TFSA})_{2}$ : (a) $0.5 \mathrm{~mol} \mathrm{dm}^{-3}-1.0$ mol dm ${ }^{-3}$. (b) $1.0 \mathrm{~mol} \mathrm{dm}^{-3}-0.5 \mathrm{~mol} \mathrm{dm}^{-3}$.

electrolytes with (a) $0.5 \mathrm{~mol} \mathrm{dm}^{-3}$, (b) $1.0 \mathrm{~mol} \mathrm{dm}^{-3}$ for the concentration of $\mathrm{L}_{x} \mathrm{MgCl}$ (total $\mathrm{Mg}$ concentration $1.5 \mathrm{~mol} \mathrm{dm}^{-3}$ ) are shown in Fig. 4. When the concentration of $\mathrm{L}_{x} \mathrm{MgCl}$ is $0.5 \mathrm{~mol} \mathrm{dm}^{-3}$, conductivities at $298 \mathrm{~K}$ for the both ternary electrolytes are similar because the main salt in these electrolytes are $\mathrm{Mg}(\mathrm{TFSA})_{2}$. From the low temperature conductivities of 0.5 
mol dm ${ }^{-3} \mathrm{~L}_{x} \mathrm{MgCl}$ electrolytes and the $1.0 \mathrm{~mol} \mathrm{dm}^{-3} \mathrm{~L}_{x} \mathrm{MgCl}$ cases at wider temperature region, $\mathrm{L}_{\mathrm{BU}}$ provides lower conductivity compared with $\mathrm{L}_{\mathrm{DMA}}$. The lower conductivity of the $\mathrm{L}_{\mathrm{BU}} \mathrm{MgCl}-$ containing electrolyte is somewhat in relation to the low mobility of $\mathrm{Mg}$ active species observed as small deposition-dissolution peak current in Fig. 3(c). It is noteworthy that a phenoxyimine ligand is expected to be included in an anion complex and a complex cation is a multi-nuclear magnesium chloride, as discussed in detail in a previous paper. Therefore, a phenoxyimine ligand $\mathrm{L}_{x}$ is considered to contribute to the change in the structure of magnesium chloride complex and/or the ion conduction circumstance, such as viscosity.

Cyclic voltammograms of magnesium deposition in the $\mathrm{L}_{x} \mathrm{MgCl} /$ $\operatorname{Mg}(\mathrm{TFSA})_{2} /$ triglyme mixed electrolytes with ca. $0.1 \mathrm{~mol} \mathrm{dm}^{-3}$ $\mathrm{AlCl}_{3}$ are presented in Figs. 3(d, e) for $\mathrm{L}_{\mathrm{DMA}} \mathrm{MgCl}$ and $\mathrm{L}_{\mathrm{BU}} \mathrm{MgCl}$. The effect of $\mathrm{AlCl}_{3}$ addition to the electrolyte differs by the $\mathrm{L}_{x}$ ligand. As reported previously, ${ }^{29}$ the Coulombic efficiency of magnesium deposition-dissolution is improved from $43 \%$ to $81 \%$ by the addition of $\mathrm{AlCl}_{3}$. By contrast, in the electrolyte containing $\mathrm{L}_{\mathrm{BU}} \mathrm{MgCl}$, the addition of $\mathrm{AlCl}_{3}$ provides little influence on the Coulombic efficiency of magnesium deposition-dissolution: $88 \%$ and $83 \%$, respectively, with and without addition of $\mathrm{AlCl}_{3}$.

The magnesium deposition properties of the electrolyte containing $\mathrm{L}_{x} \mathrm{MgCl}$ are strongly influenced by a tailing group of the phenoxyimine ligand. However, a means of influencing the electrochemical reaction is somewhat complicated. In fact, it can be estimated from some indirect indications such as Raman results and molecular orbital calculations. Some results are presented in Fig. 5 and Table 1. In the ligand design strategy, the terminal dimethylamino group in $\mathrm{L}_{\mathrm{DMA}}$ coordinates magnesium ion and forms a tri-dentate complex. However, Fig. 3 suggests that the dimethylamino group does not participate in coordination to magnesium. The terminal group, the dimethylamino for $\mathrm{L}_{\mathrm{DMA}}$ and

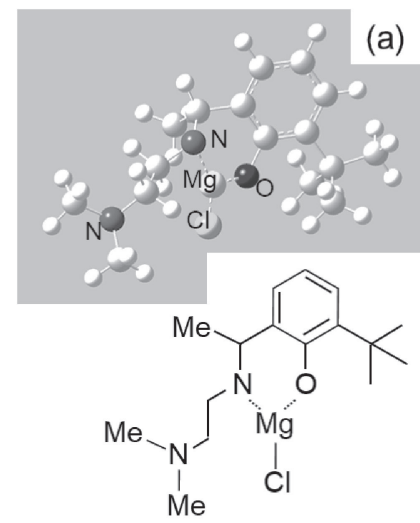

(b)

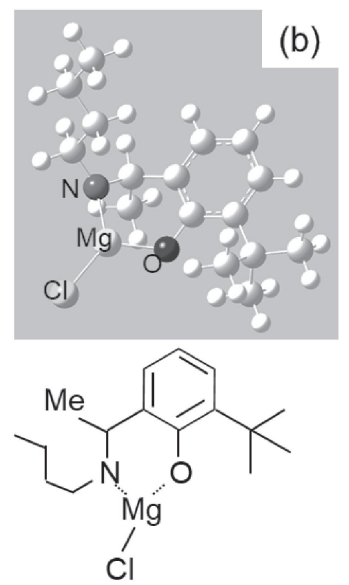

Figure 5. Optimized coordination structure of $\mathrm{L}_{x} \mathrm{MgCl}$ by molecular orbital calculation. (a) $\mathrm{L}_{\mathrm{DMA}} \mathrm{MgCl}$. (b) $\mathrm{L}_{\mathrm{BU}} \mathrm{MgCl}$.
Table 1. Some values obtained from molecular orbital calculations.

\begin{tabular}{lcc}
\hline & $\mathrm{L}_{\mathrm{DMA}} \mathrm{MgCl}$ & $\mathrm{L}_{\mathrm{BU}} \mathrm{MgCl}$ \\
\hline Mg-O distance $/ \mathrm{nm}$ & 0.1914 & 0.1898 \\
$\mathrm{Mg}-\mathrm{Cl}$ distance $/ \mathrm{nm}$ & 0.2296 & 0.2330 \\
Mulliken charge on $\mathrm{Mg}^{+}$ & +0.600 & +0.845 \\
Mulliken charge on $\mathrm{Cl}^{-}$ & -0.517 & -0.542 \\
\hline
\end{tabular}

the n-butyl for $\mathrm{L}_{\mathrm{BU}}$, is directed rather outside of the cluster. In addition, as presented in Table 1, the positivity of magnesium is reduced to a greater degree on the $\mathrm{L}_{\mathrm{DMA}} \mathrm{MgCl}$ than on the $\mathrm{L}_{\mathrm{BU}} \mathrm{MgCl}$, i.e., $\mathrm{L}_{\mathrm{BU}}$ coordinates at a more ionic mode than $\mathrm{L}_{\mathrm{DMA}}$ does. Such a difference in the polarization between $\mathrm{Mg}-\mathrm{Cl}$ may provide an influence on the following difference in the structure of $\mathrm{Mg}-\mathrm{Cl}$ complex. For $\mathrm{L}_{\mathrm{DMA}} \mathrm{MgCl}$, the structures of complex cation and anion have already been monitored by X-ray diffraction and indicated in a previous study. ${ }^{29}$

Raman spectra of $0.5 \mathrm{~mol} \mathrm{dm}^{-3} \quad \mathrm{~L}_{x} \mathrm{MgCl} / 1.0 \mathrm{~mol} \mathrm{dm}^{-3}$ $\mathrm{Mg}(\mathrm{TFSA})_{2} /$ triglyme at a selected region of $700-950 \mathrm{~cm}^{-1}$ without the addition of $\mathrm{AlCl}_{3}$ are presented in Fig. 6(a). In this region, electrolytes, irrespective of the ligand, delivered peaks for asymmetric deformation of $-\mathrm{CF}_{3}$ from $\mathrm{TFSA}^{-}$, and $\mathrm{C}-\mathrm{O}-\mathrm{C}$ stretching at $741 \mathrm{~cm}^{-1}$ and around $800-900 \mathrm{~cm}^{-1}$, respectively. ${ }^{31}$ The peak at $741 \mathrm{~cm}^{-1}$ has only a negligible split at higher wavenumber, and thus $\mathrm{TFSA}^{-}$is suggested to exist as a free ion without coordinating with $\mathrm{Mg}^{2+}$. The $\mathrm{C}-\mathrm{O}-\mathrm{C}$ peak has two marked splits at 860 and $875 \mathrm{~cm}^{-1}$. The peaks of these fractions differ because of the added $\mathrm{L}_{x} \mathrm{MgCl}$ complex: The $\mathrm{L}_{\mathrm{BU}} \mathrm{MgCl}$ delivers a larger peak at $875 \mathrm{~cm}^{-1}$ than with the $\mathrm{L}_{\mathrm{DMA}} \mathrm{MgCl}$ analogue. According to detailed spectroscopic studies for electrolyte containing magnesium chloride, ${ }^{14,32,33}$ the peak at $860 \mathrm{~cm}^{-1}$ is assigned to the $-\mathrm{CH}_{2}-\mathrm{O}-\mathrm{CH}_{2}-$ coordinated with $\mathrm{Mg}^{2+}$. The peak at $875 \mathrm{~cm}^{-1}$ is assigned to triglymes coordinated in $\mathrm{Mg}^{2+}$ with TFSA ${ }^{-}$and chloride ion in $\mathrm{Mg}(\mathrm{TFSA})_{2} / \mathrm{MgCl}_{2} /$ triglyme concentrated solution (rigorously, other band than $860 \mathrm{~cm}^{-1}$ ). In any case, the latter peak includes the contribution of some $\mathrm{Cl}-\mathrm{Mg}$-triglyme coordination and suggests the existence of expected active species for magnesium deposition in magnesium chloride-based electrolytes. The $\mathrm{L}_{\mathrm{BU}} \mathrm{MgCl}$ containing electrolyte includes a more significant amount of $\mathrm{Cl}-$ $\mathrm{Mg}$-triglyme coordination than the $\mathrm{L}_{\mathrm{DMA}} \mathrm{MgCl}$ analogue, where the coordination of $\mathrm{Mg}^{2+}$-triglyme might be preferred.

Raman spectra for the $\mathrm{AlCl}_{3}$-added electrolytes containing $\mathrm{L}_{\mathrm{DMA}} \mathrm{MgCl}$ or $\mathrm{L}_{\mathrm{BU}} \mathrm{MgCl}$ shown in Fig. 6(b) indicate different features. The $\mathrm{CF}_{3}$-peak at $741 \mathrm{~cm}^{-1}$ splits into several fractions. The main peak becomes smaller. The change in the $\mathrm{C}-\mathrm{O}-\mathrm{C}$ peak might be readily apparent. The split at $860 \mathrm{~cm}^{-1}$ is greater for the $\mathrm{L}_{\mathrm{BU}} \mathrm{MgCl}$-containing electrolyte than with the $\mathrm{L}_{\mathrm{DMA}} \mathrm{MgCl}$ analogue.
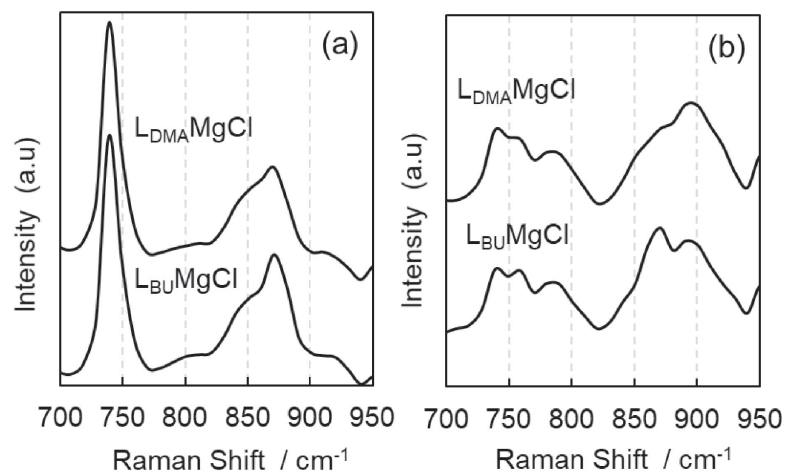

Figure 6. Raman spectra of $\mathrm{Mg}(\mathrm{TFSA})_{2} / \mathrm{L}_{x} \mathrm{MgCl} /$ triglyme electrolytes. (a) Without addition of $\mathrm{AlCl}_{3}$. (b) With addition of $\mathrm{AlCl}_{3}$. 
In these cases, the ion pair contact $\mathrm{Mg}^{2+}-\mathrm{TFSA}^{-}$appears to increase for both $\mathrm{L}_{x}$ ligands. Furthermore, the $\mathrm{Mg}^{2+}$-triglyme complex coordination appears to be greater than the active $\mathrm{Cl}-\mathrm{Mg}$-triglyme coordination in the $\mathrm{L}_{\mathrm{BU}} \mathrm{MgCl}$-containing electrolyte. Under the existence of the $\mathrm{L}_{\mathrm{BU}}$ ligand, the addition of $\mathrm{AlCl}_{3}$ accelerates the formation of $\mathrm{Mg}^{2+}-$ TFSA-triglyme type contact ion pairs more than it accelerates $\mathrm{Cl}-\mathrm{Mg}$-triglyme coordination. This change in coordinating equilibrium in the solution might correspond to the lack of a marked effect of the $\mathrm{AlCl}_{3}$ addition on magnesium deposition-dissolution. By contrast, the addition of $\mathrm{AlCl}_{3}$ equilibrates the formation of the $\mathrm{Mg}-\mathrm{Cl}$-triglyme complexes because of the existence of the $\mathrm{L}_{\mathrm{DMA}} \mathrm{MgCl}$, as reported for many Cl-containing electrolytes.

The electrochemical behavior, Raman results, and molecular orbital calculations all indicate that the $\mathrm{L}_{\mathrm{BU}}$ ligand might change the Schlenk-type equilibrium and might thereby accelerate the formation of some active triglyme- $\mathrm{Mg}-\mathrm{Cl}$ coordination. That formation might include multi-nuclear complex ions such as $\mu$ $\mathrm{Mg}_{2} \mathrm{Cl}_{3}{ }^{+}$or $\mu-\mathrm{Mg}_{3} \mathrm{Cl}_{4}{ }^{2+}$ (with coordination by solvent molecules) by its polarized structure by raising the equilibrium concentration of chloride. The increase of active triglyme- $\mathrm{Mg}-\mathrm{Cl}$ coordination aids the dissolution of deposited magnesium. However, the effect of $\mathrm{AlCl}_{3}$ addition is not strong in the $\mathrm{L}_{\mathrm{BU}} \mathrm{MgCl}$-containing electrolyte, for reasons that remain unclear. $\mathrm{AlCl}_{3}$ might act as a trapper for chloride ions through the following reaction.

$$
\mathrm{Cl}^{-}+\mathrm{AlCl}_{3} \rightleftarrows \mathrm{AlCl}_{4}^{-}
$$

If $\mathrm{AlCl}_{4}{ }^{-}$complex ion is somewhat stabilized, then the equilibrium concentration of chloride ion might decrease. As a result, the $\mathrm{Mg}^{2+}-$ $\mathrm{TFSA}^{-}$-triglyme contact ion pair might become favorable, thereby decreasing the electrolyte activity. In the cases presented herein, $\mathrm{AlCl}_{3}$ is added only in small and insufficient amounts such that $\mathrm{AlCl}_{4}{ }^{-}$might act as a stable ion, not as a sink or source of chloride ion, in particular for the $\mathrm{L}_{\mathrm{BU}} \mathrm{MgCl}$-based electrolyte. Increasing the $\mathrm{AlCl}_{3}$ amount might improve the formation of triglyme- $\mathrm{Mg}-\mathrm{Cl}$ coordination and improve the Coulombic efficiency for magnesium somewhat, but the high viscosity of the mixed electrolyte would allow only slow $\mathrm{AlCl}_{3}$ dissolution. Little information exists to elucidate changes of $\mathrm{AlCl}_{3}$ in the $\mathrm{L}_{\mathrm{BU}} \mathrm{MgCl}$-containing electrolyte. Therefore, further discussion must be undertaken to reveal the effects of $\mathrm{AlCl}_{3}$.

\section{Conclusion}

The deposition-dissolution behavior of magnesium in the mixed electrolyte containing phenoxyimine-coordinated magnesium chloride is influenced by the terminal group structure of the phenoxyimime ligand. The ligand with an n-butyl terminal in the mixed electrolyte provides higher Coulombic efficiency than that of the phenoxyimine ligand with dimethylamine terminal, although the coexistence of coordinated magnesium chloride improves the magnesium dissolution of $\operatorname{Mg}(\operatorname{TFSA})_{2} /$ triglyme electrolyte, irrespective of the terminal group. Molecular orbital calculation results suggest that the n-butyl terminal ligand is more polar than the other ligand, and that changes occur in the equilibrium of the magnesiumchloride-triglyme system to form active triglyme-magnesiumchloride coordinated species. By contrast, adding a small amount of $\mathrm{AlCl}_{3}$ is ineffective for improving magnesium reversibility in this electrolyte, probably because of chloride ion trapping and the decrease of active species. Molecular design of a ligand for this electrolyte system is possible, but the influence of ligand structure on the solution and electrochemical properties are difficult to predict directly from the ligand molecular structure.

\section{Acknowledgments}

This study was supported by Japan Science and Technology Agency (JST) ALCA-SPRING Grant Number JPMJAL1301, Japan. Dr. Kaori Hiratsuka, Nihon University and Ms. Satomi Takahara, Fukuoka University conducted practical experiments. The authors appreciate their contributions.

\section{References}

1. R. Mohtadi and F. Mizuno, Beilstein J. Nanotechnol., 5, 1291 (2014).

2. J. Muldoon, C. B. Bucur, and T. Gregory, Angew. Chem., Int. Ed., 56, 12064 (2017).

3. J. Song, E. Sahadeo, M. Noked, and S. B. Lee, J. Phys. Chem. Lett., 7, 1736 (2016).

4. R. Attias, M. Salama, B. Hirsch, Y. Gofer, and D. Aurbach, Joule, 3, 27 (2019).

5. H. Shuai, J. Xu, and K. Huang, Coord. Chem. Rev, 422, 213478 (2020).

6. T. D. Gregory, R. J. Hoffman, and R. C. Winterson, J. Electrochem. Soc., 137, 775 (1990).

7. C. Liebenow, J. Appl. Electrochem., 27, 221 (1997).

8. D. Aurbach, Z. Lu, A. Schechter, Y. Gofer, H. Gizbar, R. Turgeman, Y. Cohen, M. Moshkovich, and E. Levi, Nature, 407, 724 (2000).

9. D. Aurbach, H. Gizbar, A. Schechter, O. Chusid, H. E. Gottlieb, Y. Gofer, and I. Goldberg, J. Electrochem. Soc., 149, A115 (2002).

10. H. Gizbar, Y. Vestfrid, O. Chusid, Y. Gofer, H. E. Gottlieb, V. Marks, and D. Aurbach, Organometallics, 23, 3826 (2004).

11. A. Benmayza, M. Ramanathan, T. S. Arthur, M. Matsui, F. Mizuno, J. Guo, P.-A. Glans, and J. Prakash, J. Phys. Chem. C, 117, 26881 (2013).

12. I. Shterenberg, M. Salama, H. D. Yao, Y. Gofer, J.-B. Park, Y.-K. Sun, and D. Aurbach, J. Electrochem. Soc., 162, A7118 (2015).

13. N. Sa, B. Pan, A. Saha-Shah, A. A. Hubaud, J. T. Vaughey, L. A. Baker, C. Liao, and A. K. Burrell, ACS Appl. Mater. Interfaces, 8, 16002 (2016).

14. K. Shimokawa, H. Matsumoto, and T. Ichitsubo, J. Phys. Chem. Lett., 9, 4732 (2018).

15. T. Liu, Y. Shao, G. Li, M. Gu, J. Hu, S. Xu, Z. Nie, X. Chen, C. Wang, and J. Liu, J. Mater. Chem. A, 2, 3430 (2014).

16. K. A. See, K. W. Chapman, L. Zhu, K. M. Wiaderek, O. J. Borkiewicz, C. J. Barile, P. J. Chupas, and A. A. Gewirth, J. Am. Chem. Soc., 138, 328 (2016)

17. G. Bieker, M. Salama, M. Kolek, Y. Goffer, P. Bieker, D. Aurbach, and M. Winter, ACS Appl. Mater. Interfaces, 11, 24057 (2019).

18. T. S. Arthur, P.-A. Glans, M. Matsui, R. Zhang, B. Ma, and J. Guo, Electrochem. Commun., 24, 43 (2012).

19. J. G. Connell, M. Zorko, G. Agarwal, M. Yang, C. Liao, R. S. Assary, D. Strmcnik, and N. M. Markovic, ACS Appl. Mater. Interfaces, 12, 36137 (2020).

20. S. Yagi, A. Tanaka, T. Ichitsubo, and E. Matsubara, ECS Electrochem. Lett., 1, D11 (2012).

21. O. Tutusaus, R. Mohtadi, T. S. Arthur, F. Mizuno, E. G. Nelson, and Y. V. Sevryugina, Angew. Chem., Int. Ed., 54, 7900 (2015).

22. Z. Zhao-Karger, M. E. G. Bardaji, O. Fuhr, and M. Fichtner, J. Mater. Chem. A, 5, 10815 (2017).

23. R. Attias, M. S. Chae, B. Dlugatch, M. Oliel, Y. Goffer, and D. Aurbach, ACS Catal., 10, 7773 (2020).

24. H. D. Yoo, Y. Liang, H. Dong, J. Lin, H. Wang, Y. Liu, L. Ma, T. Wu, Y. Li, Q. Ru, Y. Jing, Q. An, W. Zhou, J. Guo, J. Lu, S. T. Panteilides, X. Qian, and Y. Yao, Nat. Commun., 8, 339 (2017).

25. C. Liao, B. Guo, D. Jiang, R. Custelcean, S. M. Mahurin, X.-G. Sun, and S. Dai, J. Mater. Chem. A, 2, 581 (2014).

26. T. Mandai, Y. Akita, S. Yagi, M. Egashira, H. Munakata, and K. Kanamura, J. Mater. Chem. A, 5, 3152 (2017).

27. C. Liebenow, Z. Yang, and P. Lobitz, Electrochem. Commun., 2, 641 (2000).

28. C. Liao, N. Sa, B. Key, A. K. Burrell, L. Cheng, L. A. Curttiss, J. T. Vaughey, J.-J. Woo, L. Hu, B. Pan, and Z. Zhang, J. Mater. Chem. A, 3, 6082 (2015).

29. M. Egashira, K. Hiratsuka, K. Matsubara, Y. Akita, H. Munakata, and K. Kanamura, Mater. Today Energy, 9, 279 (2018).

30. M. Egashira, K. Hiratsuka, S. Takahara, and K. Matsubara, Electrochemistry, 87, 251 (2019).

31. T. Kimura, K. Fujii, Y. Sato, M. Morita, and N. Yoshimoto, J. Phys. Chem. C, 119, 18911 (2015).

32. M. Salama, I. Shterenberg, L. J. W. Shinon, K. Keinan-Adamsky, M. Afri, Y. Gofer, and D. Aurbach, J. Phys. Chem. C, 121, 24909 (2017).

33. V. Küpers, D. Weintz, C. Mück-Lichternfeld, P. Bieker, M. Winter, and M. Kolek, J. Electrochem. Soc., 167, 160505 (2020). 